ANADOLU, J. of AARI

ISSN: $1300-0225$ (Print)

E-ISSN: 2667-6087 (Online)

2020, 30 (2): 284-294

DOI: $10.18615 /$ anadolu. 835053

\title{
Vista Bella Elma Çeșidinde Farklı Tozlayıcı Çeșitlerin Meyve Tutumu ve Bazı Meyve Kalite Özellikleri Üzerine Etkisi
}

\author{
Emre AKKURT ${ }^{1 *}$ (D) Kerem MERTOĞLU ${ }^{2}$ (D) Yasemin EVRENOSOĞLU ${ }^{3}$ \\ ${ }^{1,2,3}$ Eskişehir Osmangazi Üniversitesi, Ziraat Fakültesi \\ Bahçe Bitkileri Bölümü, Eskişehir/TURKEY \\ ${ }^{1}$ https://orcid.org/0000-0002-4451-3946 $\quad{ }^{2}$ https://orcid.org/0000-0002-0490-9073 \\ ${ }^{3}$ https://orcid.org/0000-0002-0212-8492 \\ * Corresponding author (Sorumlu yazar): emre.akkurt13@gmail.com \\ Received (Geliş tarihi): 10.06.2020Ａccepted (Kabul tarihi): 21.07.2020
}

\begin{abstract}
ÖZ: 2018 ve 2019 yıllarında yürütülen bu çalışmada, yazlık grupta yer alan 'Vista Bella' çeşidine yine yazlık grupta yer alan 'Summer Red', 'Williams Pride' ve 'Jersey Mac' çeşitlerinin tozlayıcı olarak kullanılabilme potansiyelleri tespit edilmiştir. Sonuçlar doğrultusunda, 'Vista Bella' çeşidinin kendilenmesi neticesinde, meyve tutumunun \%10,68 düzeyinde kaldiğ ve kısmen kendine uyuşmaz olduğu görülmüş̧ür. Çeşitlerin, çiçek tozu canlılı̆̆l ve çimlenme oranları sirası ile \%74,33 - \%67,00 ve \%44,33 - 45,67 aralıklarında bulunurken, tam çiçeklenme tarihlerinin örtüştügü görülmüştür. Ayrıca, yüksek meyve tutum oranı $(\% 26,12$ - 33,62) neticesinde, çeșitler arasında, gametofitik olarak uyușmazlık olmadĭ̆ kanaatine varılmıştır. Ancak, elde edilen meyvelerde, çekirdek sayılarının kritik düzeyde olması sebebi ile minimum iki farkl çeşidin tozlayıcı olarak kullanılması gerektiği ortaya çıkmış olup, 'Summer Red' ve 'Jersey Mac' çeşitlerinin, 'Vista Bella' çeşidine tozlayıcı olarak kullanılması durumunda, fitokimyasal özellikleri nispeten iyileştirdiği tespit edilmiştir. Korelasyon analizleri sonucunda, meyve tutum miktarında meydana gelen artışın fitokimyasal birikimi azalttığı, buna karşıı asitliğin artması ile birikimin teşvik edildiği bulunmuştur. Ayrıca antioksidan aktivitenin, toplam fenol $\left(r=0,57^{* * *}\right)$ ve $C$ vitamin $\left(r=0,31^{*}\right)$ ile pozitif ilişki içerisinde olduğu tespit edilmiştir.
\end{abstract}

Anahtar Kelimeler: Meyve tutumu, çiçek tozu, kendileme, uyuşma, fenolik bileşikler.

\section{Effects of Different Pollinator Cultivars on Fruit Set and Different Fruit Quality Characteristics on Vista Bella Apple Cultivar}

\begin{abstract}
This study was carried out in 2018 and 2019 in order to determine the potential of using "Summer Red", "Williams Pride" and "Jersey Mac" varieties as a pollinator for "Vista Bella". As a result of self pollination in 'Vista Bella', fruit set was remained at $10.68 \%$. In line with this result, 'Vista Bella' variety was found to be partially incompatible with itself. Pollen viability and germination rates of cultivars ranged between $67.00-74.33 \%$ and $44.33-45.67 \%$ respectively. Full blooming dates of cultivars were overlapped and there was no gametophytic incompatibility between cultivars thanks to high fruit set rate (26.12 - 33.62\%). However, it has been revealed that minimum two different varieties should be used as pollinators due to the critical number of seeds in the obtained fruit. 'Summer Red' and 'Jersey Mac' varieties are relatively improved phytochemical properties when used as pollinator for 'Vista Bella'. As a result of the correlation analysis, it was found that increase of fruit set caused a decrease in phytochemical accumulation, while accumulation was triggered by acidity increase. In addition, antioxidant activity was found to be in positive relationship with total phenol $(r=0.57 * * *)$ and vitamin $C(r=0.31 *)$.
\end{abstract}

Keywords: Fruit set, pollen, self-pollination, compatibility, phenolic compounds. 


\section{GİRIŞ}

Elma, zengin genetik tabanı sayesinde, Dünya üzerinde çok geniş yayılma alanı gösteren ve değişik ekolojilerde üretimi yapılabilen bir türdür (Urrestarazu ve ark., 2016). Elmanın orjin merkezleri arasında yer alan Türkiye'de, ülkenin ekolojik ve topoğrafik yapısından kaynaklı yetiştirilen birçok farklı elma tür ve çeşidi bulunmaktadır (Ercisli, 2004). FAO'nun 2017 yılı verilerine göre, dünyada 83.139.326 ton elma üretilmiş olup, Türkiye 3.032.164 tonluk üretimi ile üçüncü sırada bulunmakta olup, üretici ülkeler arasında yer almaktadır. Üretilen elma miktarının yaklaşık 9.043.972 tonu ülkeler arasında ticarete söz konusu olarak, elmayı dış ticarette önemli bir ürün haline getirmektedir (Anonymous, 2017).

Elma yetiştiriciliğini ekonomik ve sürdürülebilir olmakta zorlayan en önemli etkenlerden birisi, Sallellerine bağlı olarak görülen gametofitik uyuşmazlık mekanizmasidır (Ramírez ve Davenport, 2013). Çeşitlerin birçoğu kendine verimli olmamakla birlikte, diğer çeşitlerle de uyuşmazlık göstermektedir. $\mathrm{Bu}$ durumun gözetilmediği durumlarda, meyve tutumunun çok düşük seviyelerde kaldığı ve ciddi ekonomik kayıpların yaşandığ (Gülcan ve ark., 2001; Korkmaz ve ark., 2015).

Yeni geliştirilen çeşitler veya introdüksiyon materyalinin, fenolojik seyri ve döllenme biyolojileri oldukça önemlidir. Nitekim kendine ve diğer çeşitler ile olan uyuşma durumuna ilaveten, tozlamayı takiben başarılı bir döllenme olabilmesi için, çeşitlerin çiçeklenme dönemlerinin örtüşmesi gerekmektedir. Bu doğrultuda yürütülen çalıșmalar neticesinde, 'Starkrimson', 'Braeburn', 'Red Chief', 'Fuji', 'Jonathan', 'Golden Delicious', 'Rome Beauty', 'Oldenburg', 'Wealty', 'Yellow Transparent', 'Galia Beauty', 'Grimes Golden' çeşitlerinin büyük oranda kendi ile uyuşmaz oldukları tespit edilirken, 'Elstar', 'Idared', 'Royal Gala', 'Megumi' ve 'Orin' çeşitlerinin kısmen veya tamamen kendine verimli oldukları bildirilmektedir (Özçağıran ve ark., 2005; Așkın ve ark., 2006; Ramírez ve Davenport, 2013; Vizzotto ve ark., 2018).
Tozlayıcı olarak kullanılan çeşitlerin meyve tutumuna olan olumlu etkilerinin yanında meyve kalite parametrelerine olan katkıları da önem arz etmektedir. Metakseni olarak adlandirılan bu durum, uygun tozlayıcı seçiminde dikkat edilmesi gereken başlıca konular arasında görülmektedir (Jahed, 2015). Bu bağlamda, hasat edilen meyvelerde biyokimyasal içeriğin tozlayıcıya bağlı olarak değişiminin belirlenmesi önem taşımaktadır. Son dönemde, farkındalık düzeyi artan toplumların, antioksidan türevi bileşikleri (organik - fenolik asitler gibi) daha fazla içeren ürünlere yöneldiği ifade edilmektedir (Demir ve Aktaş, 2018). Bu bileșiklerin, oksidanlara bir hidrojen molekülü vererek, hidroksil radikali yapısında yer alan hidrojen atomları ile bağ oluşturabilecek ürünlerin ortamdan temizlenmesini, böylelikle oksidasyon ve peroksidasyon reaksiyonlarının başlamasını önledikleri bildirilmektedir (Dai ve Mumper, 2010). $\mathrm{Bu}$ antioksidatif etkinin, kanser ve kardiyovasküler hastalıklar dahil olmak üzere, pek çok kronik hastalığın görülme riskini düşürdügü belirtilmektedir (Tang ve Tsao, 2017; Pham ve ark., 2019). Fitokimyasal çeşitliliğin ve miktarın yüksek olması, bitkilerin savunma mekanizmasını da olumlu etkilemekte, bitkinin biyotik ve abiyotik stres koşullarına toleransını arttırmaktadır (Günen ve ark., 2005; Sklodowska ve ark., 2018).

$\mathrm{Bu}$ açıklamalar 1şığında planlanan bu çalışmada, yazlık grupta yer 'Vista Bella' elma çeşidinin, kendine uyuşma durumu ve yine yazlık grupta bulunan farklı çeşitlerin ('Summer Red', 'Williams Pride' ve 'Jersey Mac') bu çeşit ile uyuşma durumlarının belirlenmesi amaçlanmıştır. Ayrıca bu çeşitlerin, tozlayıcı olarak meyve biyokimyasal özellikleri üzerine olan etkileri de tespit edilmiştir.

\section{MATERYAL ve METOT}

Çalışmada materyal olarak, Eskişehir Osmangazi Üniversitesi, Ziraat Fakültesi deneme arazilerinde bulunan ve 2008 yılında, 'MM106' anacina aş11 halde araziye dikilen 'Vista Bella' çeşidi ana ebeveyn olarak kullanılmıştır. 'Jersey Mac', 'Summer Red', 'Williams Pride' ve 'Vista Bella' (kendileme) çeşitleri ise tozlayıcı olarak seçilmiş olup, çalışma 2018-2019 yıllarında yürütülmüştür. 
Çalıșma materyalinin bulunduğu Eskişehir (Merkez) ilinde, tipik karasal iklim görülmekte olup, çalışma döneminde deneme yerinde gözlenen iklimsel özellikler Çizelge 1'de verilmiştir. Küresel iklim değişikliğine bağlı olarak, her iki deneme yılında da, hava sicaklıklarının uzun dönem ortalamasına göre daha yüksek düzeyde olduğu gözlenmiştir. Hava sıcaklıklarının artması, havada su buharı çözünme potansiyelini arttırdığından, hava oransal neminde de, benzer eğilim gözlenmiş̦tir. Yağış miktarı bakımından, uzun yıllar verileri incelendiğinde, mevsimlerin ayları arasında tutarlılık olduğu görülürken, çalışmayı kapsayan y1llarda düzensiz yağışlar ve kurak dönemler gözlemlenmiştir.

\section{Çeşitlere ait tam çiçeklenme, çiçek tozu canlılık ve çimlendirme özelliklerinin belirlenmesi}

Çeşitlerin, tam çiçeklenme zamanı, ağaç üzerinde bulunan çiçeklerin yaklașık \%70-80 oranında açtığı dönem olarak kaydedilmiştir (Bostan, 1990).

Melezleme ve çiçek tozu canlılık-çimlendirme çalışmaları için ihtiyaç duyulan çiçek tozları, sabah güneș doğumundan 2-3 saat sonra açmaya hazır, beyaz çiçek tomurcuklarının yeterli miktarda toplanması ile elde edilmiştir. $\mathrm{Bu}$ tomurcuklardan çıkarılan anterler elişi kâğıdı konmuş tepsi üzerinde, oda sıcaklığında 24 saat bekletilmiştir. Anterlerin patlaması sonucu saçılan çiçek tozları cam şişelere toplanmıştır. Canlılık düzeylerini saptayabilmek amaciyla, Norton (1966) tarafindan belirtilen şekilde hazırlanan 2,3,5 Tripyhenyl Tetrazolium Chlorid (TTC) boya çözeltisi kullanılmıştır. Her çeşit için 3 lam-lamel ve her lam-lamel üzerinde 3 bölgede, ekim işleminden 2 saat sonra mikroskop yardımı ile sayım gerçekleştirilmiştir. Sayımlar sırasında kırmızı boyanan çiçek tozları canlı olarak değerlendirilmiş ve sayılan toplam çiçek tozuna oranlanarak, çiçek tozu canlılığı hesaplanmıştır (Eti, 1991).

Çiçek tozu çimlenme oranlarının belirlenmesi amaciyla; \%1 agar, \%15 sakkaroz ve 5 ppm borik asit içeren besiyeri ortamı hazırlanmış ve her genotip için 3 petri kutusuna ekim gerçekleştirilmiş ve oda sicaklığında, karanlık ortamda inkübasyona bırakılmıştır. Yaklaşık 4 saat sonra her petri kutusunda, mikroskop altında 5 bölgede sayım yapılmıştır. Çimlenen çiçek tozlarının, sayılan toplam çiçek tozu sayısına oranlanması ile çeşitlere ait çimlenme yüzdeleri tespit edilmiştir (Eti, 1991; Aşkın ve ark., 2006).

\section{Melezleme, serbest tozlama ve meyve tutum oranının saptanması}

Melezleme çalışmasında, elmanın erselik çiçekleri, açmaya yakın dönemde penslerle emasküle edilmiştir. $\mathrm{Bu}$ amaçla, işaretlenen dallarda, çiçeklerin, taç yaprak ve anterleri uzaklaştırılmıştır. Bir gün sonrasında ise daha önce elde edilmiş çiçek tozları ile tozlama yapılmıştır (Layne ve Quamme, 1975). Her melezleme kombinasyonunda, 3 farklı ağaç ve 4 farklı yöneyden, toplamda en az 250 çiçek ile çalışılmıştır. Tozlama işlemi etkili tozlanma periyodu ile çakıștırılmak istendiğinden, emaskülasyonu takip eden 2. gün tekrar edilmiştir. Serbest tozlamada ise sayılan çiçeklerde herhangi bir uygulama yapılmamış olup, sadece etiketleme gerçekleştirilmiştir. Meyve tutum oranı (\%); ilk tozlama işleminden sonraki 40. günde, sayılan meyve sayısının tozlanan çiçek sayısına bölünmesi ve elde edilen sayının 100 ile çarpılması şeklinde belirlenmiştir.

Çizelge 1. Araştırma alanına ait iklimsel veriler (Anonim, 2020).

Table 1. Climatic data of research area (Anonim, 2020).

\begin{tabular}{|c|c|c|c|c|c|c|c|c|c|}
\hline \multirow{2}{*}{$\begin{array}{l}\text { Aylar-Y1llar } \\
\text { Months-Years }\end{array}$} & \multicolumn{3}{|c|}{$\begin{array}{c}\text { Yağış }(\mathrm{mm}) \\
\text { Precipitation }(\mathrm{mm})\end{array}$} & \multicolumn{3}{|c|}{$\begin{array}{c}\text { Nem (\%) } \\
\text { Humidity (\%) }\end{array}$} & \multicolumn{3}{|c|}{$\begin{array}{l}\text { Sicaklik ( C) } \\
\text { Temperature }(\mathrm{C})\end{array}$} \\
\hline & 2018 & 2019 & $\begin{array}{l}\text { Uzun yillar } \\
\text { Long terms }\end{array}$ & 2018 & 2019 & $\begin{array}{l}\text { Uzun yillar } \\
\text { Long terms }\end{array}$ & 2018 & 2019 & $\begin{array}{l}\text { Uzun yillar } \\
\text { Long terms }\end{array}$ \\
\hline Mart (March) & 53,6 & 9,2 & 30,3 & 73,5 & 64,5 & 65,1 & 9,2 & 6,3 & 5,3 \\
\hline Nisan (April) & 12,6 & 24,8 & 40,5 & 61,6 & 69,3 & 62,8 & 13,8 & 9,5 & 9,9 \\
\hline Mayıs (May) & 62,2 & 39,8 & 41,9 & 74,8 & 65,1 & 60,8 & 16,8 & 16,5 & 14,8 \\
\hline Haziran (June) & 46,6 & 36,6 & 29,9 & 69,5 & 67,9 & 57,2 & 19,9 & 20,9 & 18,9 \\
\hline Temmuz (July) & 39,2 & 36,4 & 14,2 & 65,5 & 62,4 & 53,0 & 22,3 & 21,3 & 21,9 \\
\hline Ağustos (August) & 18,0 & 3,2 & 12,42 & 63,5 & 61,0 & 54,7 & 22,9 & 22,3 & 21,8 \\
\hline Eylül (September) & 2,8 & 4,0 & 16,98 & 65,4 & 62,1 & 58,4 & 18,6 & 18,3 & 17,3 \\
\hline
\end{tabular}




\section{Meyvede biyokimyasal analizler}

Kendileme ve melezlemeler sonucu tutan meyveler, kopma tabakasının oluşumu ve tat kriterleri göz önünde bulundurularak, hasat edilmiştir. Her bir ağacın meyveleri, diğerleri ile karıştırılmaksızın hasat edilmiş olur, analizler için örneklemeler, ağacın tüm yöneylerini temsil edecek şekilde yapılmıştır. Örneklenen, 10 meyve katı meyve suyu sikacağ 1 ile meyve suyuna dönüştürülerek, Whatman filtre kağıdı aracılığı ile süzülmüştür. Analizlerin tamamında bu meyve suları kullanılmıştır.

Titre edilebilir asitlik tayininde, meyve sular1, fenolftalein indikatörlüğünde, $0,1 \mathrm{~N}$ Sodyum hidroksit çözeltisi ile titre edilmiş ve sonuçlar, Karaçalı (2012)'nın belirttiği formüle göre hesaplanarak, malik asit cinsinden \% olarak ifade edilmiştir. Vitamin C miktarının saptanmasında volumetrik titrasyon yöntemi kullanılmıștır (Spinola ve ark., 2013). Yönteme göre nişasta indikatör olarak kullanılmış ve potasyum iyodür ile titre edilmiştir. Spinola ve ark., (2013)'nın, belirttiği formül doğrultusunda hesaplamalar yapılmış ve sonuçlar $\mathrm{mg} 100 \mathrm{~mL}^{-1}$ olarak verilmiştir. Toplam fenol miktarının belirlenmesinde ise Folin-Ciocalteu yöntemi, Selcuk ve Erkan (2016)'in belirtiği şekilde yürütülmüştür. Standart eğrinin hazırlanmasında, gallik asit kullanılmış ve sonuçlar mg GAE L ${ }^{-1}$ olarak ifade edilmiştir. Antioksidan aktivite tayininde, DPPH yöntemi kullanılmış olup, Polat ve ark, (2018)'nın belirttiği yöntem üzerinde bazı modifikasyonlar yapılarak gerçekleştirilmiştir. \% 50 inhibisyon sağlayan numune konsantrasyonu (IC50) tespit edildikten sonra, her çeşitten IC50 değeri kadar alınan örneklerin, DPPH radikalini giderme kabiliyetleri tespit edilmiş olup, sonuçlar $\%$ olarak ifade edilmiştir. Meyve sularının, toplam flavonoid içeriğini belirlemede, alüminyum klorür kolorimetrik yöntemi kullanılmıştır (Chang ve ark., 2002). Standart eğrinin oluşturulmasında, kateşin kullanılmış ve toplam flavonoid içeriği mg catechin $100 \mathrm{~mL}^{-1}$ eşdeğeri olarak ifade edilmiştir.

\section{Verilerin değerlendirilmesi}

2018 ve 2019 yıllarında yürütülen bu çalışmanın deneme tasarım $5 \times 2$ (tozlayıc1 $\mathrm{x}$ yıl) faktöriyel düzende tesadüf parselleri deneme desenine göre kurulmuştur. Çeşitlere ait çiçek tozu özellikleri,
Minitab-17 paket programında, tek yönlü ANOVA prosedürü kullanılarak tespit edilmiştir. Farklı tozlayıcıların, incelenen özellikler üzerine olan etkileri ise GLM prosedüründe, faktör ve faktörlerin interaksiyonları kombinlenerek gerçekleştirilmiştir. Çeşitler arasındaki farklılıklar ise \% 5 önem düzeyinde Tukey (HSD) çoklu karşılaştırma testi ile ortaya konulmuștur. Özellikler arasındaki ilişkiler, korelasyon analizleri ile tespit edilmiş olup, sonuçlar Pearson korelasyon katsayıları ile ifade edilmiştir (Düzgüneş ve ark., 1987).

\section{BULGULAR ve TARTIŞMA}

Çeşitlerin çiçek tozu canlılık ve çimlenme oranlarına ait bulgular Çizelge 2'de verilmiştir. Sonuçlar doğrultusunda, çeşitlere ait çiçek tozu çimlenme oranları \%45 düzeyinde bulunmuş olup istatistiksel olarak fark tespit edilmezken, çiçek tozu canlılık değerleri arasındaki farklılıklar, istatistiksel olarak önemli bulunmuştur. 'Vista Bella' çeşidine ait çiçek tozlarının canlılık oranı $\% 74,33$ ile en yüksek değeri alırken, bu çeşidi sirasiyla 'Summer Red' $(\% 71,33)$, 'Jersey Mac' $(\% 69,33)$ ve 'Williams Pride' takip etmiştir $(\% 67,00)$. Farklı elma çeşitleri ile yürütülen çalışmalarda, çiçek tozu canlılığının, \%75,0 - 84,4 (Muradoğlu ve ark., 2019); \%5,2 - 82,4 (Erdem ve Çekiç, 2016); \%47,45 - 85,75 (Eti ve ark., 1998) ve çimlenme oranının, \%8.76 - 53.00 (Erdem ve Çekiç, 2016); \%9,70 - 64,42 (Eti ve ark., 1998); $\% 42,80$ - 59,60 (Atasay ve ark., 2013) aralıklarında değişim gösterdiği bildirilmektedir. Çalışma sonuçları, önceki çalışmalar ile benzerlik göstermesine rağmen, bu özellikler üzerine; yetiştiriciliğin yapıldığı yörenin ekolojik şartları, yetiştiricilik faktörleri, çeşit, çiçeklerin toplanma dönemleri ve kültürel işlemler gibi birçok unsur etki etmekte olup, sonuçlar bu etkenlerin kümülatif etkisi altında değişiklik göstermektedir (Eti ve ark., 1998; Atasay ve ark., 2013; Mertoğlu ve ark., 2018).

Çeşitlere ait tam çiçeklenme tarihleri 25-27 Nisan arasında değişmiş olup, fenolojik olarak çeşitlerin birbiri için tozlayıcı olarak kullanılabileceği görülmüştür. Şanlıurfa koşullarında aynı çeşitlerle yapılan çalışmada tam çiçeklenme tarihleri 3-7 Nisan olarak belirlenirken (İkinci ve Bolat, 2016), 2010 ve 2011 yıllarında Eskişehir koşullarında gerçekleştirilen çalışmada, 2010 yılında Williams 
Pride ve Summer Red çeşitleri Nisanın 2-4. haftası, 'Vista Bella' çeşidi Nisanın 4. haftası tam çiçeklenmede iken, 2011 yılında 'Williams Pride' ve 'Summer Red' çeşitleri Mayısın 1-2. Haftası, 'Vista Bella' çeșidi ise Mayısın 2-3. haftası tam çiçeklenme döneminde tespit edilmiştir (Karaman Kılınç ve Evrenosoğlu, 2013). Bu araştırmanın bulguları, Şanlıurfa koşullarında yapılan çalışma ile bölgesel iklim değişiklikleri nedeniyle farklı bulunurken, Eskişehir koşullarında gerçekleştirilen çalışma ile benzerlik göstermektedir.

Vista Bella elma çeşidine ait meyvelerde; antioksidan aktivite hariç incelenen tüm özellikler üzerine, tozlayıcı ve yıl faktörleri önemli farklılıklara sebep olmuştur. Ayrıca, faktörlerin interaksiyonu da bazı özelliklerin istatistiksel düzeyde değişkenlik göstermesine neden olmuştur (Çizelge 3).

Elde edilen sonuçlar doğrultusunda, en yüksek SÇKM, pH ve TEA değerleri sırası ile $\% 13,96,3,28$ ve $\% 1,12$ ile 'Vista Bella'nın kendilenmesinden elde edilirken, 'Williams Pride' çeşidinin tozlayıcı olduğu kombinasyon SÇKM $(\% 9,99)$ ve TEA $(\% 0,96)$, 'Jersey Mac' çeşidinin tozlayıcı olduğu kombinasyon ise $\mathrm{pH}(3,22)$ özelliği bakımından en düşük değerde tespit edilmiştir. Toplam fenol özelliği bakımından tozlayıcı olarak en etkili sonucu 'Williams Pride' gösterirken (698,68 mg GAE L'), bu çeşidi sırası ile 'Summer Red'(637,82 mg GAE
L'), 'Jersey Mac' (619,31 mg GAE L'), Serbest tozlama $\left(566,73 \mathrm{mg} \mathrm{GAE} \mathrm{L}^{-}\right)$ve kendileme $(519,72$ GAE $\mathrm{L}^{-}$) takip etmiştir. $\mathrm{C}$ vitamini miktarı üzerine tozlayicilar; serbest tozlama $\left(4,01 \mathrm{mg} 100 \mathrm{ml}^{-1}\right)>$ 'Jersey Mac' (3,25 mg $\left.100 \mathrm{ml}^{-1}\right)>$ 'Summer Red' $\left(3,01 \mathrm{mg} 100 \mathrm{ml}^{-1}\right)>$ Kendileme $\left(2,84 \mathrm{mg} 100 \mathrm{ml}^{-}\right.$ $\left.{ }^{1}\right)>$ 'Williams Pride' $\left(2,64 \mathrm{mg} 100 \mathrm{ml}^{-1}\right)$ şeklinde sıralanırken, antioksidan aktivite bakımından istatistiksel düzeyde önemlilik tespit edilmemiştir.

Qin ve ark (2000), tarafindan 'Fuji' elma çeşidi, farklı çeşitler ile tozlanmış ve sonuç olarak 'Starkrimson'ın 'Fuji' için en iyi tozlayıcı olduğu belirlenmiş olup, bu çeşidin tozlayıcı olması durumunda, meyve renklenmesini, suda çözünebilir kuru maddeyi ve depolama ömrünü iyileştirdiği bildirilmiştir. Davarynejad ve ark (1993) elma üzerine yürüttükleri çalışmada, tozlayıcıların meyve kalitesi üzerine olan etkilerini belirlemek için 32 farklı kombinasyon oluşturmuşlardır. 'Duncan Red Delicious', 'Golden Delicious' 'ldared' ve 'Gloster' ile tozlama sonucu elde edilen meyvelerin, önemli ölçüde daha yüksek sertlik, titre edilebilir asitlik ve $\mathrm{C}$ vitamini miktarına sahip olduğu bildirilmiştir. Stasiak ve ark (2019) farklı tozlayıcıların etkisini belirlemek için gerçekleştirdiği çalışmada, meyve kuru madde ve fenolik bileşiklerin, polen kaynaklarından büyük ölçüde etkilendiğini, ancak askorbik asit içeriğinin etkilenmediğini bildirmişlerdir.

Çizelge 2. Çeşitlere ait tam çiçeklenme, çiçek tozu canlılığı ve çimlenme oranları.

Table 2. Pollen viability, germination rates and full bloom date of the cultivar.

\begin{tabular}{lccc}
\hline $\begin{array}{l}\text { Çeşitler } \\
\text { Varieties }\end{array}$ & $\begin{array}{c}\text { Çiçek tozu canlılı̆̆ }(\%) \\
\text { Pollen viability (\%) }\end{array}$ & $\begin{array}{c}\text { Çiçek tozu çimlenme oranı (\%) } \\
\text { Germination rates (\%) }\end{array}$ & $\begin{array}{c}\text { Tam çiçeklenme tarihi } \\
\text { Full bloom date }\end{array}$ \\
\hline Vista Bella & $74,33 \pm 0,88 \quad$ a & $44,67 \pm 1,20$ & 27.04 .2019 \\
Summer Red & $71,33 \pm 0,67 \quad$ ab & $45,67 \pm 0,88$ & 25.04 .2019 \\
Jersey Mac & $69,33 \pm 0,88 \quad$ bc & $45,67 \pm 0,88$ & 27.04 .2019 \\
Williams Pride & $67,00 \pm 1,00 \quad$ c & $44,33 \pm 2,96$ & 25.04 .2019 \\
\hline P $(<0,05)$ & $* *$ & Ö.D (N.S) & \\
Ortalama (Mean) & 70,50 & 45,08 \\
Standart sapma (Standart deviation) & 3,09 & 2,61 & \\
CV $(\%)$ & 4,38 & 5,79 & 1,35 \\
HSD $(0,05)$ & 1,28 & &
\end{tabular}

Ö.D (N.S): Önemli değil (Non significant) HSD: Tukey değeri, †her sütunda, farklı harflerle gösterilen ortalamalar arasındaki farklılıklar, istatistiksel olarak önemlidir $(*: \mathrm{p}<0.05, * *: \mathrm{p}<0.01, * * *: \mathrm{p}<0.001)$.

HSD: Tukey value, $\uparrow$ differences between the averages shown with different letters in each column are statistically significant $(*: \mathrm{p}<0.05, * *$ : $\mathrm{p}<0.01, * * *: \mathrm{p}<0.001)$. 
E. AKKURT, K. MERTOĞLU, Y. EVRENOSOĞLU: VISTA BELLA ELMA CESIDINDDE FARKLI TOZLAYICI ÇEŞITLERIN MEYVE TUTUMU VE BAZI MEYVE KALITE ÖZELLIKLERİ ÜZERINE ETKISİ

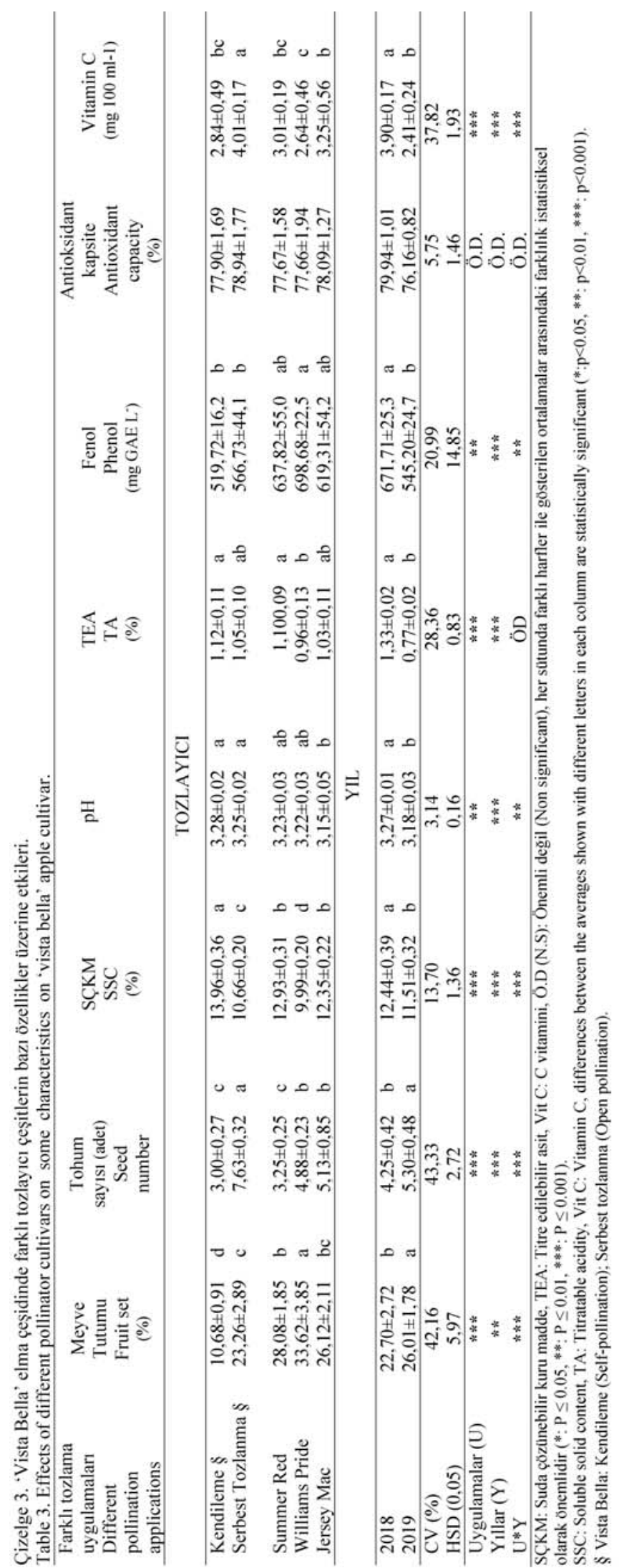


Meyve tutumu bakımından en yüksek değer, 'Vista Bella' x 'Williams Pride' kombinasyonunda $(\% 33,62)$ say1lırken, en düşük değer, 'Vista Bella' çeşidinin kendilenmesinde bulunmuştur $(\% 10,68)$ (Çizelge 2). Kendileme uygulaması ekonomik meyve tutumu için yetersiz görülürken, diğer çeşitlerin yeterli olduğu gözlenmiştir. Çalışma bulguları, elmada, farklı tozlayıcıların meyve tutumuna etki ettiği yönünde olup, Jahed'in (2015) S- allellerine bağli olarak görülen gametofitik uyuşmazlık sebebiyle, bazı çeşitlerin kısmen veya tamamen kendine verimsiz rapor edilmesi ile uyumludur. Serbest tozlanma sonucu elde edilen meyveler, tohum sayısının ( 7,63 adet) fazla olmas1 ile ön plana çıkarken, kendileme (3,0 adet) ve Summer Red' (3,25 adet) uygulamaları bu özellik bakımından en düşük değerde tespit edilmiştir. Childers ve ark (1995), elmada sağliklı bir tozlanma ve döllenme gerçekleştirilmesi için minimum 5 adet tohum bulunması gerektiğini bildirmişlerdir. $\mathrm{Bu}$ bağlamda, 'Vista Bella' çeșidi ile bahçe tesisi yapılması durumunda, mutlak suretle minimum iki adet uygun tozlayıcının, bahçe içerisine yeterli sayıda ve homojen olarak dağıtılması gerektiği düşünülmektedir.

Yıllar arasında, antioksidan aktivite bakımından istatistiksel olarak fark bulunmazken, SÇKM, $\mathrm{pH}$, TEA, toplam fenol ve vitamin $\mathrm{C}$ özelliklerinin tamamında, önemlilik tespit edilmiş olup, bu özellikler denemenin ilk yılında daha yüksek düzeylerde saptanmıştır (Çizelge 3). 2018 yılında siras1 ile \%12,44, 3,27, \%1,33, 671,71 mg GAE L', $3,90 \mathrm{mg} 100 \mathrm{ml}^{-1}$ düzeylerinde ölçülen bu özellikler 2019 y1linda \%115,51, 3,18, \%0,77, 545,20 mg
GAE L', 2,41 mg $100 \mathrm{ml}^{-1}$ seviyelerine kadar düşmüştür. Meydana gelen bu düşüşe temel olarak meyve tutum miktarında meydana gelen artışın sebep olduğu düșünülmektedir. Nitekim 2018 y1lında, \%22,70 olarak belirlenen meyve tutum düzeyi, 2019 yılında \%26,01 düzeyine yükselmiştir. Mertoğlu ve ark. (2019) tarafindan, meyve tutum miktarının yükselmesi ile asimilasyon ürünlerinin daha fazla meyveye paylaştırılmasından kaynaklı biyokimyasal birikimin azaldığı ifade edilmektedir.

Meyve tutumu ve tohum sayısı değerleri açısından da yıllar arasındaki fark önemli olup, 2019 y1lındaki değerler $(26,01$ ve 5,30) 2018 y1lına $(22,70$ ve 4,25$)$ göre daha yüksek bulunmuştur (Çizelge 2). Bu farklılıkların yıllara göre değişen iklimsel sebeplerden ileri geldiği düşünülmektedir. Hava sıcaklıklarındaki hızlı değişimler, nem ve yağış gibi parametreler; meyve türlerinin tozlanması ve döllenmesi üzerine oldukça önemli olup, bu parametrelerde meydana gelen değişimler; meyve tutumu, tohum sayısı ve şekli gibi birçok özelliği etkilemektedir (Omoto ve Aono, 1990; Zavalloni ve ark., 2004; Guédon ve ark., 2008; Legave ve ark., 2008). Çalışmada, meyve tutumu, tohum sayısı, SÇKM, pH, TEA, toplam fenol miktarı ve C vitamini özelliklerinin, tozlayıc1*yıl interaksiyonlarının önemli bulunmuş olması, bu durum ile uyumludur.

'Vista Bella' çeşidinde incelenen farklı özelliklerin birbirleri ile olan ilişkilerine ait bulgular Çizelge 4'te, uygulamalara ait meyveler ise Şekil 1'de görülmektedir.

Çizelge 4. 'Vista Bella' çeşidine ait farklı uygulamalarda incelenen özelliklere ait korelasyon değerleri.

Table 4. Corelation value of investigated chracteristics in different applications of 'Vista Bella' cutivar.

\begin{tabular}{|c|c|c|c|c|c|c|c|c|c|c|c|c|c|}
\hline $\begin{array}{l}\text { İncelenen özellikler } \\
\text { Investigated } \\
\text { chracteristics }\end{array}$ & $\begin{array}{l}\text { SÇKM } \\
\text { SSC }\end{array}$ & & $\begin{array}{l}\mathrm{pH} \\
\mathrm{pH}\end{array}$ & & $\begin{array}{l}\text { C Vit. } \\
\text { Vit. C }\end{array}$ & & $\begin{array}{l}\text { TEA } \\
\text { TA }\end{array}$ & & $\begin{array}{l}\text { TFM } \\
\text { TPC }\end{array}$ & & $\begin{array}{l}\text { AA } \\
\text { AA }\end{array}$ & & $\begin{array}{l}\text { MT } \\
\text { FS }\end{array}$ \\
\hline $\mathrm{pH}(\mathrm{pH})$ & 0,19 & & & & & & & & & & & & \\
\hline $\mathrm{C}$ vit (Vit C) & 0,04 & & $-0,31$ & * & & & & & & & & & \\
\hline TEA (TA) & 0,42 & $* *$ & $-0,47$ & $* *$ & 0,69 & $* * *$ & & & & & & & \\
\hline TFM (TPC) & $-0,18$ & & $-0,59$ & $* * *$ & 0,21 & & 0,45 & $* *$ & & & & & \\
\hline AA (AA) & 0,05 & & $-0,52$ & $* *$ & 0,31 & * & 0,50 & $* *$ & 0,57 & $* * *$ & & & \\
\hline MT (FS) & $-0,51$ & $* *$ & $-0,39$ & * & $-0,03$ & & $-0,24$ & & $-0,02$ & & $-0,32$ & * & \\
\hline TS (SN) & $-0,52$ & ** & 0,03 & & 0,01 & & $-0,32$ & * & $-0,20$ & * & $-0,06$ & & 0,33 \\
\hline
\end{tabular}

SÇKM: Suda çz̈zünebilir kuru madde, C vit: C vitamini, TEA: Titre edilebilir asit, TFM: Toplam fenol miktarı, AA: Antioksidan aktivite, MT: Meyve tutumu, TS: Tohum sayısı, Önemli değil (Non significant), her sütunda farklı harfler ile gösterilen ortalamalar arasındaki farklılık istatistiksel olarak önemlidir (*: $\mathrm{P} \leq 0.05, * *: \mathrm{P} \leq 0.01, * * *: \mathrm{P} \leq 0.001)$.

SSC: Soluble solid content, Vit C: Vitamin C, TA: Titratable acidity, TPC: Total phenol content, AA: antioxidant activity, FS: Fruit set, SN: Seed number, differences between the averages shown with different letters in each column are statistically significant $\left(*: p<0.05,{ }^{* *}: \mathrm{p}<0.01,{ }^{* * *}\right.$ : $\mathrm{p}<0.001)$ 
Meyve tutum miktarı ile fitokimyasal özellikler arasında negatif ilişki tespit edilirken, istatistiksel düzeyde önemlilik; SÇKM $\left(-0,52^{* *}\right)$, TEA $\left(-0,32^{*}\right)$ ve toplam fenol miktarı $\left(-0,27^{*}\right)$ ile tespit edilmiştir. $\mathrm{Bu}$ duruma, verim artışı ile birlikte asimilasyon ürünlerinin, daha fazla meyveye paylaştırılmış olmasından kaynaklanabilir. Meyve tutumunda meydana gelen artışın, fitokimyasal birikimi azaltıcı şekilde değiştirdiği, benzer çalışmalarda ifade edilmektedir (Öztürk ve ark., 2012; Mertoğlu ve ark., 2019). Elde edilen sonuçlar, üretimde standardizasyonun sağlanabilmesi için ürün yükünün ne derece önemli olduğunu işaret etmektedir. Bu sebeple, seyreltme işleminin, yetiştiricilikte mutlak suretle uygulanması gerekmektedir. Tohum say1s1, fitokimyasal birikimi azaltmış görünse de, bu etkinin meyve tutumunun artmasından kaynaklı meydana geldiği düşünülmektedir. Zira, tohum sayıs1, meyve tutum miktarı ile yükselme eğilimi göstermiş olup, bu iki özellik arasında pozitif korelasyon tespit edilmiştir $(0,33 *)$.

Toplam organik asitlerin, hakim asit cinsinden hesaplanmış hali olan TEA ile $\mathrm{pH}$ özellikleri arasında kuvvetli ve negatif yönlü ilişki $(-0,47 * *)$ tespit edilmiştir. $\mathrm{H}^{+}$iyonu taşıyan organik asitlerin parçalanması neticesinde, $\mathrm{pH}$ değerinde yükselme meydana gelmekte olup, bu iki özellik arasındaki negatif ilişki, elmada, Mertoğlu ve Evrenosoğlu (2019), tarafindan $-0,81^{* * *}$ olarak benzer şekilde bildirilmektedir. $\mathrm{C}$ vitamininin etken maddesi olan askorbik asit ve askorbik asidin oksidasyon ürünleri ile toplam fenolü oluşturan fenolik bileşikler, asidik karakterde olup, ortamın asitliği yükseldikçe bu bileşiklerin miktarında artış olduğu belirtilmektedir (Mertoglu ve Evrenosoglu, 2019). Çalışmada da, TEA ile vitamin $C\left(0,69^{* * *}\right)$ ve toplam fenol miktarı $\left(0,45^{* *}\right)$ arasında yüksek düzeyde ilişki tespit edilmiştir. TEA ile pozitif ilişki içerisinde tespit edilen bu özelliklerin tamamı, pH ile tersi yönde etkileşim halinde bulunmuştur. Elde edilen sonuçlar, literatür ile paralel bulunmuştur (Vieira ve ark., 2009; Gunduz ve ark., 2015; Mertoglu ve Evrenosoglu, 2019).

Antioksidan aktivite ile toplam fenol ve $\mathrm{C}$ vitamini özellikleri arasında belirlenen korelasyon katsayıları sirası ile $r=0,57 * * *$ ve $r=0,31 *$ değerlerinde bulunarak, bu özellikler arasında pozitif ilişkinin olduğu sonucu elde edilmiştir. Pozitif yönde olan ilişkinin, fenol özellikte olan bu bileşikler ile askorbik asidin yüksek antioksidan özellik göstermelerinden kaynaklı olduğu söylenebilir. Zira Giampieri ve ark (2015) ve Schempp ve ark (2016), fenolik bileşiklerin yüksek antioksidan aktivite gösterdiklerini belirtmişlerdir. Toplam fenol, vitamin $\mathrm{C}$ ve antioksidan aktivite özellikleri arasında pozitif korelasyonun varlığı, elma (Mertoğlu ve Evrenosoğlu, 2019) türünün de dahil olduğu birçok meyve türünde bildirilmektedir (Koley ve ark., 2016; Dong ve ark., 2019; Chang ve ark., 2019). Asitliğin, antioksidan bileşikleri arttırıc1 etkisi sebebiyle, TEA ve antioksidan aktivite $\left(0,50^{* *}\right)$ arasında önemli pozitif ilişki ortaya çıkmıştır.
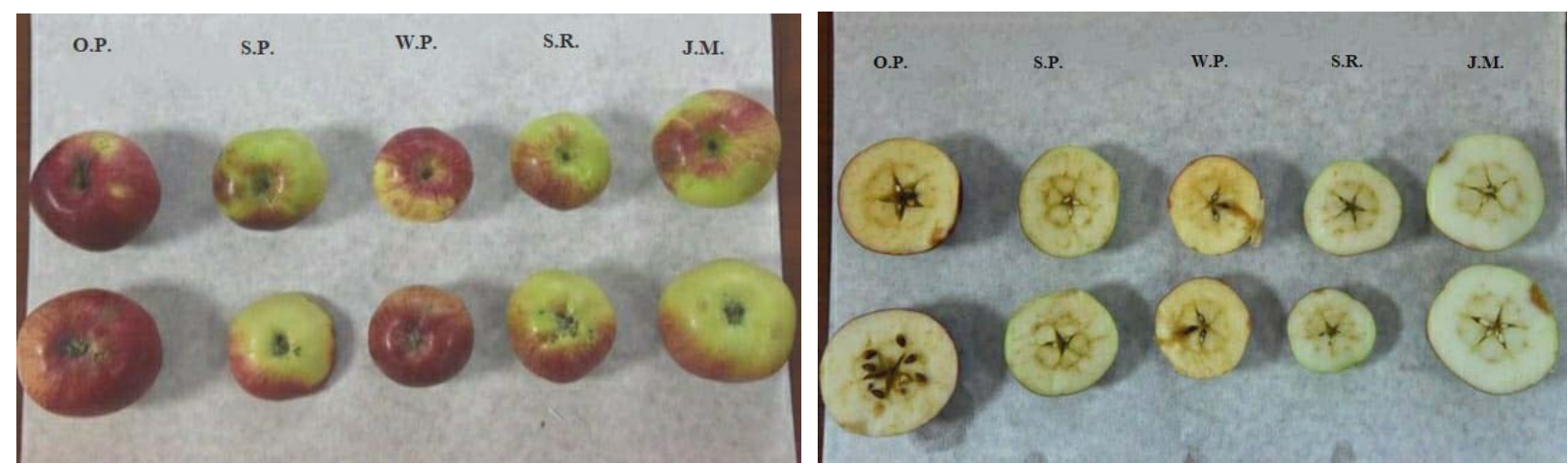

Şekil 1. 'Vista Bella' çeşidinde farklı tozlayıcıların kullanıldığı uygulamalara ait meyveler. OP: Serbest tozlama, SP: Kendileme, WP: Williams Pride, SR: Summer Red, JM: Jersey Mac.

Figure 1. Fruits of the applications of different pollinators in 'Vista Bella' variety. OP: Open pollination, SP: Self pollination, WP: Williams Pride, SR: Summer Red, JM: Jersey Mac. 


\section{SONUÇLAR}

Çalışma neticesinde, 'Vista Bella' elma çeşidinin kısmen kendine verimli olduğu tespit edilmiştir. Tozlayıc1 olarak kullanılan 'Summer Red', 'Williams Pride' ve 'Jersey Mac' çeşitlerinin hem fenolojik hem de gametofitik olarak 'Vista Bella' çeşidinde tozlayıcı olarak kullanılabileceği görülmüştür. Ayrıca tüm bu çeşitlerin polen canlılık ve çimlenme oranları da yeterli düzeyde bulunmuştur. Ancak, tohum sayılarının kritik düzeyde bulunması sebebiyle düzenli ürün elde edilmesinin, minimum iki farklı çeşitle sağlanabileceği kanaatine varılmıştır. Bu bağlamda, fitokimyasal özellikleri nispeten iyileștiren 'Summer Red' ve 'Jersey Mac' çeşitlerinin, 'Vista Bella' çeşidine tozlayıcı olarak kullanılmasının uygun olacağı söylenebilir.

\section{LITTERATÜR LISSTESI}

Anonim. 2020. 2015 Eskişehir merkez meteorolojik verileri. Meteoroloji 3. Bölge Müdürlüğü, Eskişehir. Erişim tarihi: Nisan, 2020.

Anonymous. 2017. FAOSTAT Online Statistical Service. Available from: http://faostat.fao.org (Erişim tarihi: Nisan, 2019). United Nations Food and Agriculture Organization, FAO, Roma.

Aşkın, M., A. G. Öztürk, H. C. Sarısu ve A. Karakuş. 2006. Bazı yeni elma çeşitlerinde uygun tozlayıcı çeşidin ve kendine verimlilik durumunun belirlenmesi. SDÜ Ziraat Fakültesi Dergisi 11 (1): 64-73.

Atasay, A., H. Akgül, K. Uçgun, and B. Şan. 2013. Nitrogen fertilization affected the pollen production and quality in apple cultivars "Jerseymac" and "Golden Delicious". Acta Agriculturae Scandinavica, Section B-Soil \& Plant Science 63 (5): 460-465. Doi:10.1080/09064710.2013.798683.

Bostan, S. Z. 1990. Van ve çevresinde yetistirilen mahalli armut çesitlerinin morfolojik ve pomolojik özellikleri üzerine arastırmalar. Yüzüncü Y1l Üniversitesi, Fen Bilimleri Enstitüsü, Yüksek lisans Tezi, Van Yüzüncü Y1l Üniversitesi. Fen Bilimleri Enstitüsü, Van, 79 s.

Chang, C. C, M. H. Yang, H. M. Wen, and J. C. Chern. 2002. Estimation of total flavonoid content in propolis by two complementary colorimetric methods. Journal of Food and Drug Analysis 10 (3): 178-182.

Chang, Y. L, J. T. Lin, H. L. Lin, P. L. Liao, P. J. Wu, and D. J. Yang. 2019. Phenolic compositions and antioxidant properties of leaves of eight persimmon varieties harvested in different periods. Food Chemistry 289: 74-83. Doi: 10.1016/j.foodchem.2019. 03.048.
C vitamini ve toplam fenol, antioksidan özellikte tespit edilirken, asitliğin artması bu bileşiklerin miktarını olumlu etkileyerek, yükselmelerini sağlamıştır. Bu bağlamda, meyve biyokimyasının iyileştirilmesi için asitliği yüksek genotiplerin geliştirilmesi, ümitvar görülmektedir.

\section{TEŞEKKÜR}

$\mathrm{Bu}$ çalışma Emre AKKURT tarafından Eskişehir Osmangazi Üniversitesi Ziraat Fakültesi, Bahçe Bitkileri Bölümü'nde yürütülen 'Bazı yazlık elma çeşitlerinde farklı tozlayıcı çeşitlerin meyve tutum oranı ve bazı meyve özelliklerine etkilerinin belirlenmesi' isimli yüksek lisans tezininin bir bölümünü oluşturmaktadır.

Childers, N. F, J. R. Morris, and G. S. Sibbett. 1995. Modern Fruit Sscience: Orchard and Small Fruit Culture. 10th. Edition, 583 pages. ISBN 13: 9780938378013.

Dai, J., and R. J. Mumper. 2010. Plant phenolics: extraction, analysis and their antioxidant and anticancer properties. Molecules 15 (10): 7313-7352. Doi:10.3390/molecules 15107313.

Davarynejad, G., H. J. Nyéki, J. Hámori Szabó, and Z. Lakner. 1993. Relationship between pollen-donors and quality of fruits of 12 apple cultivars. In International Symposium on Postharvest Treatment of Horticultural Crops 368: 344-354. Doi:10.17660/Acta Hortic.1994.368.43.

Demir, G., and N. Aktaş. 2018. A research on functional food knowledge, preference and consumption of university students. Üniversite öğrencilerinin fonksiyonel besin bilgi, tercih ve tüketimleri üzerine bir araştırma. Journal of Human Sciences 15 (4): 2387-2397.

Dong, X., Y. Hu, Y. Li, and Z. Zhou. 2019. The maturity degree, phenolic compounds and antioxidant activity of Eureka Lemon [Citrus limon (L.) Burm. f.]: A negative correlation between total phenolic content, antioxidant capacity and soluble solid content. Scientia Horticulturae 243: 281-289. Doi:10.1016/ j.scienta. 2018.08.036.

Düzgüneş, O., T. Kesici, O. Kavuncu ve F. Gürbüz. 1987. Araştırma ve Deneme Metotları (İstatistik metotlar1II), Ankara Üniversitesi Ziraat Fakültesi Yayınları No. 1021, 381s, Ankara.

Ercisli, S. 2004. A short review of the fruit germplasm resources of Turkey. Genetic Resources and Crop Evolution 51 (4): 419 - 435. Doi:10.1023/ B:GRES.0000023458.60138.79. 
Erdem, S. Ö. ve Ç. Çekiç. 2016. Elma ve ayva çeşitlerinde çiçeklenmenin farklı dönemlerindeki çiçek tozlarının canlılık ve çimlenme oranlarının belirlenmesi. International Journal of Agricultural and Natural Sciences 9 (1): 01-04.

Eti, S. 1991. Bazı meyve tur ve ceşitlerinde değişik in vitro testler yardımıla cicek tozu canlılık ve cimlenme yeteneklerinin belirlenmesi. C.U. Ziraat Fakültesi Dergisi 6 (1): 69-80.

Eti, S., N. Kaşka, A. Küden, and M. Ilgın, 1998. Investigations on the fertilization biology of some summer apple varieties. Turkish Journal of Agriculture and Forestry 22 (2): 111-116.

Giampieri, F., T. Y. Forbes-Hernveez, M. Gasparrini, J. M. Alvarez-Suarez, S. Afrin, S. Bompadre, and $\mathrm{M}$. Battino. 2015. Strawberry as a health promoter: An evidence based review. Food \& Function 6 (5): 13861398. Doi:10.1039/C5FO00147A.

Guédon, Y, and J. M. Legave. 2008. Analyzing the timecourse variation of apple and pear tree dates of flowering stages in the global warming context. Ecological Modelling 219 (1): 189-199. Doi:10.1016/j.ecolmodel.2008.08.010.

Gunduz, K., S. Serçe, and J. F. Hancock. 2015. Variation among highbush and rabbiteye cultivars of blueberry for fruit quality and phytochemical characteristics. Journal of Food Composition and Analysis 38: 69-79. Doi:10.1016/j.jfca.2014.09.007.

Gülcan, R., H. A. Ölmez, M. Sahin, A. Misirli, and H. Saglam. 2001. Investigations on fertilization biology of 1mportant dried apricot cultivars. In XII International Symposium on Apricot Culture and Decline 701: 159162. Doi:10.17660/ActaHortic.2006.701.23.

Günen, Y., A. Misirli, and R. Gulcan. 2005. Leaf phenolic content of pear cultivars resistant or susceptible to fire blight. Scientia Horticulturae 105 (2): 213-221. Doi:10.1016/j.scienta.2005.01.014.

İkinci, A., and İ. Bolat. 2016. Determination of phenological, pomological and yield characteristics of low chilling apple cultivars budded on M9 and MM 106 rootstocks. pp.6-9. In: VIII International Scientific Agricultural Symposium" Agrosym.

Jahed, R. K. 2015. Male and female interaction in apple: Pollen tube growth, fruit set, fruit quality, and return bloom, Open Access Theses, 495. https://docs.lib. purdue.edu/open_access_theses/495.

Karaçalı, İ. 2012. Bahçe Ürünlerinin Muhafazası ve Pazarlanması. Hasat Öncesi Dönemde Gelişmeyi Etkileyen Faktörler. Ege Üniv. Yay. No: 494. Bornova, İzmir.

Karaman Kılınç, A. ve Y. Evrenosoğu. 2013. Eskişehir koşullarında bazı elma çeşit/anaç kombinasyonlarına ait verim ve meyve özelliklerinin belirlenmesi. Ege Üniversitesi Ziraat Fakültesi Dergisi 50 (3): 323-332.
Koley, T. K., C. Kaur, S. Nagal, S. Walia, and S. Jaggi. 2016. Antioxidant activity and phenolic content in genotypes of Indian jujube (Zizyphus mauritiana Lamk.). Arabian Journal of Chemistry 9: S1044-S1052. Doi:10.1016/j.arabjc.2011.11.005.

Korkmaz, Ş., A. K. Bekir, E. Sakar, İ. Turanoğlu ve S. Söylemez. 2015. Meyve ağaçlarında uyuşmazlık ve mekanizması. Harran Tarım ve Gıda Bilimleri Dergisi 19 (3): 180-186.

Layne, E. C., and H. A. Quamme. 1975. Pears, pp. 38-70. In: Janick J, Moore JN (Eds.). Advances in Fruit Breeding. Purdue University Press, West Lafayette, Indiana.

Legave, J. M., I. Farrera, T. Almeras, and M. Calleja. 2008. Selecting models of apple flowering time and understanding how global warming has had an impacton this trait. Journal of Horticultural Science $\begin{array}{llll}\text { and } & \text { Biotechnology } 83 & \text { (1): }\end{array}$ Doi:10.1080/14620316.2008.11512350

Mertoğlu, K., and Y. Evrenosoğlu. 2019. Bazı elma ve armut çeşitlerinde fitokimyasal özelliklerin belirlenmesi. Ziraat Fakültesi Dergisi 14 (1): 11-20.

Mertoğlu, K., Y. Evrenosoğlu, and M. Polat. 2019. Combined effects of ethephon and mepiquat chloride on late blooming, fruit set, and phytochemical characteristics of Black Diamond plum. Turkish Journal of Agriculture and Forestry 43 (6): 544-553. Doi:10.3906/tar-1811-65.

Mertoğlu, K., Y. Evrenosoğlu ve Y. Altay. 2018. Eskişehir ekolojisinde 0900 Ziraat kiraz çeşidine uygun tozlayıcıların belirlenmesi. Süleyman Demirel Üniversitesi Fen Bilimleri Enstitüsü Dergisi 22: 89-97. Doi:10.19113/sdufbed.24496.

Muradoğlu, F., Z. Sulum, İ. Başak ve G. Akkuş. 2019. Ağır metallerin Red Chief ve Granny Smith elma çeşitlerinde polen çimlenmesi ve polen tüpü büyümesi üzerine etkileri. Uluslararası Tarım ve Yaban Hayatı Bilimleri Dergisi 5 (1): 54-62. Doi:10. 24180/ijaws. 532092.

Norton, J. D. 1966. Testing of plum pollen viability with tetrazolium salts. Proceedings of the American Society for Horticultural Science 89: 132-134.

Omoto, Y., and Y. Aono. 1990. Estimationof change in blooming dates of cherry flowerby urban warming. Journal of Agricultural Meteorology 46: 123-129. Doi:10.2480/agrmet.46.123.

Özçağıran, R., A. Ünal, E. Özeker ve M. İsfendiyaroğlu. 2005. Ilıman İklim Meyve Türleri, Sert Çekirdekli Meyveler Cilt I. Ege Üniversitesi Ziraat Fakültesi Yayınları. No:553. 229 s. İzmir. 
Öztürk, B., Y. Özkan, K. Yıldız, Ç. Çekiç, and K. Kılıç. 2012. Red Chief elma çeşidinde aminoethoxyvinylglycine'nin (avg) ve naftalen asetik asit'in (naa) hasat önü döküm ve meyve kalitesi üzerine etkisi. Anadolu Tarım Bilimleri Dergisi 27 (3): 120-126. Doi: 10.7161/anajas.2012.273.120

Pham, T., S. Lecomte, T. Efstathiou, F. Ferriere, and F. Pakdel. 2019. An update on the effects of glyceollins on human health: Possible anticancer effects and underlying mechanisms. Nutrients 11 (1): 79. Doi: 10.3390/nu11010079.

Polat, M., V. Okatan, S.F. Güçlü, and A. M. Çolak. 2018. Determination of some chemical characteristics and total antioxidant capacity in apple varieties grown in Posof/Ardahan region. International Journal of Agriculture, Environment and Food Sciences 2 (4): 131-134. Doi: 10.31015/jaefs. 18022

Qin, L.G., Q. Y. Ming, C. Y. Hong, Y. Z. Mei, S. H. Feng, and L. Lin. 2000. Effect of metaxenia on the fruit quality of Fuji apple variety. South China Fruits 29 (1): pp.35.

Ramírez, F., and T. L. Davenport. 2013. Apple pollination: A review. Scientia Horticulturae 162: 188-203. Doi: 10.1016/j.scienta.2013.08.007.

Schempp, H., S. Christof, U. Mayr, and D. Treutter. 2016. Phenolic compounds in juices of apple cultivars and their relation to antioxidant activity. Journal of Applied Botany and Food Quality 89: 11-20. Doi:10.5073/JABFQ.2016.089.002.

Selcuk, N., and M. Erkan. 2016. Impact of passive modified atmosphere packaging on physicochemical properties, bioactive compounds, and quality attributes of sweet pomegranates, Turkish Journal of Agriculture and Forestry 40 (4): 475-488. Doi:10.3906/tar-1509-57.

Sklodowska, M., A. Mikicinski, M. Wielanek, E. Kuzniak, and P. Sobiczewski. 2018. Phenolic profiles in apple leaves and the efficacy of selected phenols against fire blight (Erwinia amylovora). European Journal of Plant Pathology 151: 213-228. Doi: 10.1007/ s10658-017$1368-5$.
Spinola, V., B. Mendes, J. S. Camara, and P. C. Castilho. 2013. Effect of time and temperature on Vitamin C stability in horticultural extracts. UHPLC-PDA vs 1odometric titration as analytical methods. LWT-Food Science and Technology 50 (2): 489-495. Doi: 10.1016/j.lwt.2012.08.020.

Stasiak, A., P. Latocha, J. Drzewiecki, E. Hallmann, K. Najman, H. Leontowicz, and B. Lata. 2019. The choice of female or male parent affects some biochemical characteristics of fruit or seed of kiwiberry (Actinidia arguta). Euphytica 215 (3): 52. Doi: 10.1007/s10681-019-2375-8.

Tang, Y., and R. Tsao. 2017. Phytochemicals in quinoa and amaranth grains and their antioxidant, anti - inflammatory, and potential health beneficial effects: A review. Molecular Nutrition \& Food Research 61 (7): 1600767. Doi: 10.1002/mnfr.201600767.

Urrestarazu, J., C. Denancé, E. Ravon, A. Guyader, R. Guisnel, L. Feugey, and F. Fernandez-Fernandez. 2016. Analysis of the genetic diversity and structure across a wide range of germplasm reveals prominent gene flow in apple at the European level. BMC Plant Biology 16 (1): 130. Doi: 10.1186/s12870-016-0818-0.

Vieira, F.G.K., G.D.S.C. Borges, C. Copetti, R.D.D.M.C. Amboni, F. Denardi, and R. Fett. 2009. Physicochemical and antioxidant properties of six apple cultivars (Malus domestica Borkh) grown in Southern Brazil. Scientia Horticulturae, 122 (3): 421-425. Doi: 10.1016/j.scienta.2009.06.012.

Vizzotto, G., E. Driussi, M. Pontoni, and R. Testolin. 2018. Effect of flower pollination on fruit set and cropping in apple. American Journal of Agriculture And Forestry 6 (5): 156-161. Doi: 10.11648/j.ajaf.2018 0605.16.

Zavalloni, C., J. A. Andresen, J. A. Winkler, J. A. Flore, J. R. Black, and T. L. Beedy. 2004. The pileus project: Climatic impact son sour cherry productionin the Great Lakes region in past and projected future time frames. VII International Symposium on Modelling in Fruit Research and Orchard Management 707: pp.101-108. Doi: 10.17660/ActaHortic.2006.707.12. 